\title{
Pratylenchus thornei: The Relationship Between Presowing Nematode Density and Yield Loss in Wheat and Barley
}

\author{
Joshua P. Fanning, ${ }^{1, \dagger}$ Karyn L. Reeves, ${ }^{2}$ Clayton R. Forknall, ${ }^{3}$ Alan C. McKay, ${ }^{4}$ and Grant J. Hollaway ${ }^{1}$ \\ ${ }^{1}$ Agriculture Victoria, Horsham, Victoria, Australia 3401 \\ ${ }^{2}$ Statistics for the Australian Grains Industry-West, Curtin University, Bentley, Western Australia, Australia 6102 \\ ${ }^{3}$ Queensland Department of Agriculture and Fisheries, Leslie Research Facility, Toowoomba, Queensland, Australia 4350 \\ ${ }^{4}$ South Australian Research and Development Institute, Adelaide, South Australia, Australia 5001 \\ Accepted for publication 13 November 2019.
}

ABSTRACT

\begin{abstract}
The root lesion nematode Pratylenchus thornei causes economic losses in wheat and barley internationally through both reduced grain yield and grain quality. This study investigated the relationships between the presowing $P$. thornei density and grain yield and the postharvest nematode densities. Four field experiments were conducted at the same site between 2010 and 2014. A range of presowing P. thornei densities was established in the first year by growing three cereal cultivars that ranged from resistant to susceptible. In the following year, plots were sown with the five same cereal cultivars. A linear relationship was observed between the natural $\log$ of the presowing P. thornei density and grain yield across all seasons. The results showed that grain yield losses varied between cultivars and seasons. The importance of season was significant, with this study conducted over several seasons, and it highlighted the variability in yield losses between seasons, which will
\end{abstract}

need further investigation. The greatest yield losses observed were 25 to $28 \%$ when the maximum presowing $P$. thornei densities ranged between 150 and 250 P. thornei $\mathrm{g}$ of soil $^{-1}$. An analysis of the relationship between the presowing and postharvest nematode densities revealed that increased presowing nematode densities resulted in decreased multiplication rates in all seasons and in all cultivars. Nematode multiplication rates also varied between seasons. These results explain why it is difficult to predict nematode levels based on cropping history, and additionally, they highlight the importance of growing resistant cultivars to maintain low levels of $P$. thornei to minimize risk of yield losses.

Keywords: disease control and pest management, cereal resistance, equilibrium point, nematology, population biology, Pratylenchus thornei, root lesion nematode, yield loss
The root lesion nematode Pratylenchus thornei causes worldwide grain yield losses in wheat (Triticum aestivum) (Mokrini et al. 2016; Ortiz-Monasterio and Nicol 2004; Smiley et al. 2005; Thompson et al. 2017). These nematodes are migratory polycyclic endoparasites that feed on and within the roots of plants, affecting root function and crop performance (Moens and Perry 2009; Thompson et al. 2012; Vanstone et al. 2008). In Australia, P. thornei has been estimated to cost the wheat and barley (Hordeum vulgare) industries $\$ 50$ and $\$ 8$ million per annum, respectively (Murray and Brennan 2009, 2010).

Reported yield losses caused by P. thornei are variable across the grain-growing regions of Australia. In northern Australia, yield loss caused by $P$. thornei in wheat crops has been well established, with losses of up to 65\% reported (Mills and Sheppard 1998; Thompson et al. 1999). However, most studies have measured differences in the grain yield of wheat cultivars exposed to high densities of $P$. thornei to select for tolerance to the nematode (Thompson 2008; Thompson et al. 1993, 1995, 1999, 2008, 2012). In other regions of Australia, there are limited reports of yield loss caused by P. thornei in wheat, and where losses have been reported, they are generally less than those reported in northern Australia (Vanstone et al. 2008).

A range of approaches has been used to assess yield loss caused by root lesion nematodes in field crops. Several studies selected

${ }^{\dagger}$ Corresponding author: J. P. Fanning; joshua.fanning@agriculture.vic.gov.au

Funding: Financial support was provided by Grains Research and Development Corporation projects DAS00099, DAV00123, DAV00128, and DAW00245 and the Victorian Government.

The author(s) declare no conflict of interest.

This article is in the public domain and not copyrightable. It may be freely reprinted with customary crediting of the source. The American Phytopathological Society, 2020. fields with high nematode densities and applied nematicides, such as aldicarb, or biocides, such as methylbromide, to suppress the nematodes in selected plots or blocks, and then, they used the yield difference between the treated and untreated areas to determine the losses caused by nematodes (Doyle et al. 1987; Eastwood et al. 1994; Smiley 2009; Smiley et al. 2014; Taylor and McKay 1993; Taylor et al. 1999; Thompson et al. 1993, 1995, 2012). Nematicides are rarely used as research tools because of their high mammalian toxicity. In drier years, it has also been hypothesized that nematicides may only reduce nematode densities in the upper soil layer and not have any influence at depth (Thompson et al. 1999), thus underestimating potential yield losses.

An alternative method to assess yield losses is to measure the grain yield of the test cultivars grown in the presence of high and low presowing nematode densities of the target nematode that were established in the previous season by growing resistant and susceptible crops (Nicol et al. 1999; Owen et al. 2014; Reen et al. 2014; Smiley and Machado 2009). Both Owen et al. (2014) and Reen et al. (2014) used this method to examine the relationship between the presowing $P$. thornei densities and grain yield of wheat, with yield losses of 0.44 and $0.09 \mathrm{t} / \mathrm{ha}$ reported with increases of $0.5, \ln$ (presowing $P$. thornei/ kilogram of soil +500$)$ and $\ln$ (presowing $P$. thornei/kilogram of soil +1$)$, respectively. The combination of these methods has been previously reported in sugar beet. The relationships between yield losses and nematode densities were extensively studied in a range of crops by Seinhorst $(1965,1967,1972)$, and the method of growing resistant and susceptible crops in rotation to differentiate nematode densities within field experiments was successfully used with sugar beet cyst nematode (Heterodera schachtii) (Kenter et al. 2014 and Schmidt et al. 1993). These alternative methods have the advantage of manipulating nematode densities throughout the soil profile; however, it is important that the crops or cultivars selected have minimal differential effects on residual soil water and nutrition (e.g., nitrogen), which will confound the measurement of the nematode 
effect on yield (Angus et al. 2015; Armstrong et al. 2019; Hannah and O'Leary 1995; Owen et al. 2014; Reen et al. 2014).

Resistance to nematodes is defined as the ability of a plant to prevent nematode reproduction compared with tolerance, which is defined as the ability of a plant to grow and yield well in the presence of nematodes (Cook and Evans 1987). Resistance levels to P. thornei vary between crops and cultivars (Dababat et al. 2019; Fanning et al. 2018; Hollaway et al. 2000; Mokrini et al. 2018; Sheedy et al. 2015). Resistance to nematodes is usually assessed by quantifying initial $(P i)$ and final $(P f)$ nematode densities in a field plot or pot in a controlled environment and ranking cultivars based on their nematode multiplication rate or reproduction ratios $(\mathrm{Pf} / \mathrm{Pi})$ (Fanning et al. 2018; Hollaway et al. 2000; Keil et al. 2009; Rodda et al. 2016; Sheedy and Thompson 2009; Taylor et al. 2000) or by ranking based on final nematode densities (Hollaway 2002; Schmidt et al. 2005; Sheedy et al. 2015).

A range of methods has been used to assess the resistance of field crops to Pratylenchus species, with most studies conducted under controlled environmental conditions (Keil et al. 2009; Sheedy and Thompson 2009; Sheedy et al. 2015), using field based approaches (Ballard et al. 2006; Dababat et al. 2019; Fanning et al. 2018; Hollaway et al. 2000; Taylor et al. 2000), and combining data collected under both controlled environment and field conditions (Rodda et al. 2016; Thompson et al. 1999). Usually, field studies are completed using a single naturally occurring nematode density that can be variable (Ballard et al. 2006; Hollaway et al. 2000; Taylor et al. 2000). Fanning et al. (2018) in their study assessed field resistance in the presence of high and low initial nematode densities that were established in the previous year using cereals with contrasting resistance/susceptibility to the target nematode and found that higher multiplication was associated with the lower initial nematode densities. This finding is consistent with the findings of Ferris (1985) who, in the studies of the nematode Meloidogyne incognita, also found higher multiplication rates with lower initial nematode densities.

Nematode densities can be quantified by extracting nematodes from soil samples and visually identifying and quantifying them (Sheedy and Thompson 2009; Sheedy et al. 2015; Smiley et al. 2014) or by measuring DNA concentration in soil using quantitative PCR (qPCR) tests (Ophel-Keller et al. 2008; Sheedy et al. 2015). In Australia, growers have access to a commercial PREDICTAB soil test (OphelKeller et al. 2008). The results from these tests can be used to inform the choice of management strategies to minimize yield losses.

To interpret results based on nematode counts or DNA concentration in soil, it is important to understand the relationship between nematode density and risk of yield loss. Growers can then make informed decisions on appropriate management strategies to implement, and plant breeders and research agencies can allocate resources to develop new resistant cultivars or other appropriate management strategies. However, to develop relationships between preplanting nematode density and potential yield loss, it is important that more than two initial nematodes densities (i.e., high and low) are used (unless the relationship is known to be linear). Only then can the effect of an initial nematode density on yield loss be predicted.

This study used a 2-year approach to experimental design. In the first year, a range of nematode densities were established by sowing crops that had differential resistance/susceptibility to $P$. thornei but were unlikely to have differential effects on potentially confounding variables such as soil, water, and nutrition. In the second year, five test cultivars were sown into the established range of nematode densities with the aims to

I. Determine the relationship between presowing $P$. thornei densities determined through a DNA-based test (PREDICTAB) and grain yield for a set of commercial wheat and barley cultivars,

II. Explore the consistency of the relationship between presowing $P$. thornei densities and grain yield for the set of cultivars across several growing seasons, and

III. Measure the multiplication of $P$. thornei for the set of cultivars in the presence of differing presowing nematode densities.

\section{MATERIALS AND METHODS}

Field site. Four 2-year field experiments were conducted within the same field at Banyena, Victoria, Australia (-36.5721, 142.7940) during the years 2010 to 2014 . The field site was selected because of the low to medium density of P. thornei (5 to 20 P. thornei g soil ${ }^{-1}$ ) and low or nondetectable densities of inoculum of other regionally important soilborne pathogens (Heterodera avenae, Fusarium pseudograminearum, Fusarium culmorum, Rhizoctonia solani, and Gaeumannomyces graminis var. tritici) determined using the PREDICTAB soil test delivered by the South Australian Research and Development Institute (Adelaide, Australia). The site has a gray cracking clay soil type, and the long-term (1889 to 2014) average rainfall per annum for the closest weather station (Rupanyup; $16 \mathrm{~km}$ from the experimental site) was $421 \mathrm{~mm}$ (Table 1) (Queensland Government 2019). The site was managed with crop rotations of vetch and fallow to maintain ideal densities of $P$. thornei (5 to 20 $P$. thornei $\mathrm{g}$ of soil $^{-1}$ ) before field experiments while limiting buildup of nontarget soilborne pathogens. Pathogen populations were monitored following each crop and before each experiment using the PREDICTAB soil test (SARDI).

Field experiments. In the first year (setup year) of each experiment, $P$. thornei densities were manipulated using three cereal cultivars with contrasting resistance/susceptibility to $P$. thornei to establish a range of presowing nematode densities (Table 2) (Fanning et al. 2018; Hollaway et al. 2000). In the second year (experimental year), the experiments were sown to five cereal cultivars, which also varied in their resistance/susceptibility to P. thornei (Table 2) (Fanning et al. 2018; Hollaway et al. 2000).

Experiments were planted following rain in late May to June (winter) (Table 3) at a rate of $70 \mathrm{~kg}$ of seed ha ${ }^{-1}$. Experimental plot sizes were $8.5 \times 1.4 \mathrm{~m}$ composed of six rows spaced at $150 \mathrm{~mm}$. Fertilizer application is reported in Table 3. Foliar diseases were controlled using a foliar fungicide application between Zadoks growth stage Z31 to Z39 in each year. Weeds were controlled using preemergent and postsowing herbicides, consistent with best grower practice. Harvest occurred following crop maturity during December (summer) (Table 3) using a plot harvester, with a weight recorded for each plot and converted to metric tons per hectare for data analysis.

Experimental design. Each experiment consisted of six replicates of 15 unique treatments, resulting from the two-way factorial treatment combination of setup year cultivars (three levels) and

TABLE 1. Summary of the monthly and annual rainfall (millimeters) for the experimental years 2010 to 2014 and the long-term mean (1889 to 2014) at Rupanyup post office (16 km from the experimental site) (Queensland Government 2019)

\begin{tabular}{|c|c|c|c|c|c|c|c|c|c|c|c|c|c|}
\hline Year & January & February & March & April & May & June & July & August & September & October & November & December & Total \\
\hline 2010 & 9 & 40 & 51 & 51 & 22 & 28 & 42 & 105 & 60 & 42 & 126 & 148 & 723 \\
\hline 2011 & 201 & 47 & 20 & 10 & 23 & 18 & 55 & 44 & 14 & 36 & 42 & 48 & 558 \\
\hline 2012 & 5 & 10 & 40 & 10 & 39 & 44 & 53 & 49 & 46 & 14 & 13 & 34 & 359 \\
\hline 2013 & 0 & 19 & 1 & 10 & 36 & 60 & 61 & 74 & 44 & 51 & 18 & 12 & 386 \\
\hline 2014 & 9 & 4 & 12 & 62 & 39 & 37 & 43 & 12 & 20 & 15 & 25 & 15 & 292 \\
\hline Mean $^{a}$ & 23 & 23 & 24 & 30 & 41 & 46 & 44 & 45 & 43 & 43 & 31 & 28 & 421 \\
\hline
\end{tabular}

a Long-term mean from 1889 to 2014. 
experimental year cultivars (five levels). In the 2011 and 2012 experimental years, the treatments were randomized according to a randomized complete block design. In the 2013 experimental year, treatments were randomized according to a split plot design, whereby the experimental year cultivars were randomized to main plots and the setup year cultivars were randomized to subplots within main plots. A similar split plot randomization of treatments was used in the 2014 experimental year; however, setup year cultivars were randomized to main plots, whereas the experimental year cultivars were randomized to subplots within main plots (the reverse of the 2013 randomization). Only data collected in the second year of experimentation (experimental year) were analyzed in this study.

Nematode quantification. In the experimental year, soil samples were taken from each plot 1 to 3 months prior to sowing and again, 1 to 3 months postharvest to measure initial $(P i)$ and final $(P f) P$. thornei densities, respectively. Each soil sample consisted of 20 cores (150-mm deep and 15-mm diameter) taken using an Accucore sampler (Spurr Soil Probes). They were sampled evenly from across each plot, with four cores taken from five locations in each plot. The cores from each plot were pooled, resulting in 300 to $500 \mathrm{~g}$ of soil in each sample. Soil samples were submitted to the PREDICTAB service at the South Australian Research and Development Institute (Adelaide, Australia) for quantification of $P$. thornei densities using qPCR (Ophel-Keller et al. 2008). Quantification of the $P$. thornei densities used specific ribosomal DNA (TaqMan) probe sequences from the whole dried soil samples, with DNA standards used to convert the qPCR results to the number of $P$. thornei per gram of dried soil.

Plant assessments. In the experimental year, 20 plants were removed from a subset of plots at anthesis, with the roots of the plants washed and visually examined for symptoms of root disease. This process was conducted for the cultivars Catalina (2011 to

TABLE 2. Cereal cultivars and their reported resistance to Pratylenchus thornei that was planted during the setup or experimental years (2010 to 2014) to explore the relationships between yield, host resistance, and populations of P. thornei

\begin{tabular}{|c|c|c|}
\hline & Cultivar resistance $^{\mathrm{a}}$ & Setup year \\
\hline \multicolumn{3}{|c|}{ Setup year cultivar (crop) } \\
\hline Tamaroi (durum ${ }^{\mathrm{b}}$ ) & Resistant & $2010-2012$ \\
\hline Yawa (durum) & Resistant & 2013 \\
\hline Chara (wheat) & Moderately resistant & $2010-2013$ \\
\hline Yitpi (wheat) & Susceptible & $2010-2013$ \\
\hline \multicolumn{3}{|c|}{ Experimental year cultivar (crop) } \\
\hline Catalina (wheat) & Moderately resistant & 2011-2014 \\
\hline Chara (wheat) & Moderately resistant & 2011-2014 \\
\hline Hindmarsh (barley) & Moderately resistant & 2011-2014 \\
\hline Derrimut (wheat) & Susceptible & 2011-2014 \\
\hline Yitpi (wheat) & Susceptible & 2011-2014 \\
\hline
\end{tabular}

a Varietal ranking based on data from Fanning et al. (2018).

b Triticum turgidum subsp. durum.

TABLE 3. Summary of the fertilizer application and sowing and harvest dates for each experiment conducted to explore the relationships between yield, host resistance, and populations of Pratylenchus thornei

\begin{tabular}{|c|c|c|c|c|}
\hline \multirow{2}{*}{$\begin{array}{l}\text { Experimental } \\
\text { year }\end{array}$} & \multicolumn{2}{|c|}{$\begin{array}{c}\text { Sowing } \\
\text { fertilizer } \\
\left(\mathrm{kg} \mathrm{ha}^{-1}\right)\end{array}$} & \multirow{2}{*}{$\begin{array}{c}\text { Sowing } \\
\text { date }^{\mathrm{a}}\end{array}$} & \multirow{2}{*}{$\begin{array}{c}\text { Harves } \\
\text { date }^{\mathrm{a}}\end{array}$} \\
\hline & $\mathrm{MAP}^{\mathrm{b}}$ & Urea & & \\
\hline 2011 & 100 & 100 & $31 / 5$ & $8 / 12$ \\
\hline 2012 & 100 & 100 & $18 / 6$ & $10 / 12$ \\
\hline 2013 & 70 & $100^{c}$ & $19 / 6$ & $15 / 12$ \\
\hline 2014 & 70 & 100 & $12 / 6$ & $1 / 12$ \\
\hline
\end{tabular}

a These details refer to the experimental year.

b Monoammonium phosphate (MAP) consists of nitrogen:phosphorus:potassium:sulfur:zinc of 10:22:0:1.5:1.

c Equally split application of fertilizer at sowing and 3 months postsowing.
2014), Derrimut (2011 to 2014), and Hindmarsh (2012 to 2014) in three replicates of all three setup nematode densities.

Statistical analysis. Yield loss relationships. Relationships describing the rate of change in grain yield as presowing $P$. thornei densities $(P i)$ increased were estimated for each of the experimental year cultivars in each of the experimental years using regression implemented in a linear mixed model framework. Presowing $P$. thornei densities were natural $\log$ transformed $[\ln (P i+1)]$ prior to analysis to linearize the relationship between the dependent and independent variables while also reducing the potential excess leverage exerted by large observed $P i$.

A continuous covariate consisting of the transformed presowing $P$. thornei densities measured on a plot basis in each experimental year was fitted as a fixed effect in the model along with terms to account for the experimental year, experimental year cultivar, and the interaction between experimental year and experimental year cultivar. Additional interactions were also fitted between the transformed presowing $P$. thornei densities and experimental year, experimental year cultivar, and their interaction. Together, these terms enabled the estimation of differential yield potentials and rates of change for each experimental year cultivar in each experimental year, where the yield potential of an experimental year cultivar is the predicted yield of a cultivar in a particular experimental year in the absence of $P$. thornei. Terms to account for the structure of the experimental design in each experiment were included in the model as random effects while using the methods of Gilmour et al. (1997) to account for natural or extraneous sources of variation in the model that arose during each experiment.

The yield potential and rate of yield change for each experimental year cultivar in each experiment were estimated from the model as empirical best linear unbiased estimators. All variance components were estimated using residual maximum likelihood (Patterson and Thompson 1971) implemented through the ASReml-R package (Butler et al. 2009) in the $\mathrm{R}$ statistical computing environment ( $\mathrm{R}$ Core Team 2019); the significance of fixed effects was tested at the $5 \%$ significance level.

Cultivar resistance. Empirical observation of the experimental data suggested that a logarithmic relationship existed between the final $(P f)$ and initial $(P i)$ nematode densities with form

$$
P f=e^{\alpha} P i^{\beta}
$$

where $\alpha$ and $\beta$ are the intercept and slope, respectively, from a linear regression of natural $\log (\ln ) P f$ on $\ln P i$. In this equation, $\beta$ has a direction interpretation with respect to how much the slope curves (i.e., $\beta=1$ would give a straight line, implying a constant multiplication rate, whereas $\beta<1$ implies that the multiplication rate is lower for higher $P i$ ). The multiplier $e^{\alpha}$ grows exponentially with $\alpha$, and the larger the $\alpha$, the faster the $P i$ multiplies. If $\alpha<0$, it implies a resistant cultivar where the resulting $P f$ will be lower than $P i$ on average.

To estimate the parameters $\alpha$ and $\beta$, an initial linear mixed model was fitted to the data regressing natural log-transformed $P f$ densities on natural log-transformed $P i$ densities, including the main effects of experimental year cultivar, experimental year, and all interactions. Terms in the treatment structure were included in the model as fixed effects, and terms to account for the structure of the experimental design in each experimental year were included in the model as random effects. A backward step regression was applied to derive a final model, with interaction terms in the fixed part of the model tested using Wald-type tests in a two-stage process. Where an interaction term was significant, indicating that at least one coefficient was significantly different from zero, individual coefficients were subsequently tested for inclusion. Models were fitted with residual maximum likelihood (Patterson and Thompson 1971) using the R software package ASReml (Butler et al. 2009; R Core Team 2019).

The equilibrium density ( $\widehat{E Q})$ of an experimental year cultivar in an experimental year is defined as the value of $P i$ at which $P f$ and $P i$ are equal. The equilibrium density could be described as the 
population maintenance line, and it biologically implies that cultivars are maintaining nematode densities over the period measured. The estimated equilibrium density $\left(\widehat{E Q}_{i j}\right)$ was derived for each experimental year cultivar $i$ in each experimental year $j$ using the formula

$$
\widehat{E Q}_{i j}=\exp \left(\frac{\hat{\alpha}_{i j}}{1-\hat{\beta}_{i j}}\right)
$$

where $\hat{\alpha}_{i j}$ and $\hat{\beta}_{i j}$ are the regression coefficients.

\section{RESULTS}

Experimental establishment. The main symptoms of root disease observed were caused by root lesion nematodes in all experimental years except for 2012, where take all (G. graminis var. tritici) was observed in a limited number of plants at low severity.

Differential initial nematode densities for each of the experimental years were successfully established (Fig. 1) as expected based on the relative resistance/susceptibility (Table 2) of the three setup cereal cultivars grown during the prior setup year.

Yield loss relationships. For grain yield, a significant interaction between experimental year, experimental year cultivar, and presowing nematode density was observed $(P=0.024)$. This interaction indicated differential rates of change in yield per unit increase in presowing $P$. thornei density between experimental year cultivars across experimental years. However, on testing the significance of the relationship between the presowing $P$. thornei density and grain yield for each experimental year cultivar in each experimental year, it was found that not every experimental year cultivar demonstrated significant yield losses in every experimental year within the study (Table 4). The experimental year cultivars Derrimut and Yitpi were the two cultivars of the five within the study that demonstrated a loss in grain yield with increased presowing $P$. thornei densities (Table 4). These yield losses were observed in both cultivars during the 2011 season, but they were only in Derrimut during the 2012 season. The predicted yield losses associated with increasing presowing $P$. thornei densities and the maximum yield losses estimated to be 28,27 , and $28 \%$ for Yitpi during 2011 and Derrimut during 2011 and 2012, respectively, are presented in Table 5. The seasonal variability of the yield losses

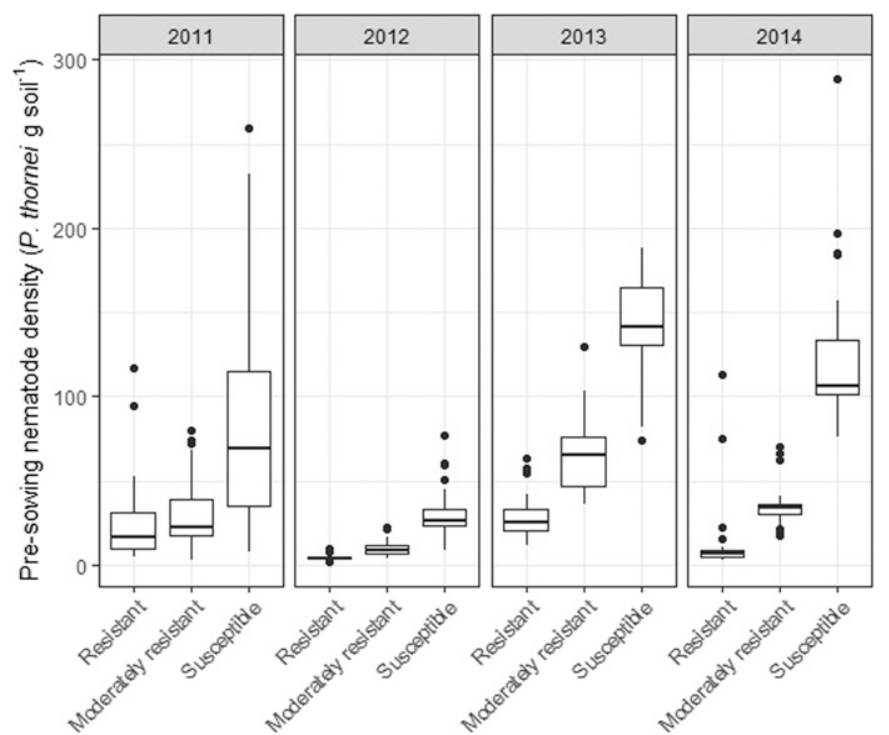

Fig. 1. The range of initial Pratylenchus thornei densities ( $P$. thornei grams of soil $^{-1}$ ) established (minimum, maximum, median, and upper and lower quartiles) in the previous year using the setup cereal cultivars Tamaroi or Yawa (resistant), Catalina (moderately resistant), and Yitpi (susceptible) at the experiment site in Banyena, Victoria. observed for the cultivar Derrimut is presented in Figure 2. In some seasons, the other three experimental year cultivars tested (cultivars Catalina, Chara, and Hindmarsh) had significant increases in grain yield associated with increases in presowing $P$. thornei densities (Table 4). These yield increases were observed from 2012 to 2014 for Catalina, in 2014 for Hindmarsh, and during 2013 and 2014 for Chara (Table 4). The predicted yield potential of the experimental year cultivars differed significantly from zero $(P<0.001)$ in all 4 experimental years.

Cultivar resistance. $P$. thornei multiplication $(P f / P i)$ varied significantly between the experimental years (calculated from Fig. 3 and Table 6$)$. This resulted in a significant $(P<0.001)$ interaction between the experimental year and experimental year cultivar. The effect of season on nematode multiplication is graphically represented (Fig. 3), where the relationship between presowing and postharvest $P$. thornei densities for the experimental year cultivar Derrimut is shown. These data highlight the differences between seasons and show that there was a narrower range of presowing nematode densities in the experimental years 2011 and 2012 compared with 2013 and 2014. The equilibrium point is reached during 2014 for Derrimut, whereas during 2011 to 2013, the equilibrium point is outside the data range.

The regression coefficients and associated errors together with the estimated equilibrium points $(P i=P f)$ calculated from the regression coefficients are presented for the relationship between presowing and postharvest $P$. thornei densities (Table 7). The estimated equilibrium points for the cultivars Derrimut and Yitpi in the experimental years 2011 to 2013 were outside the range of data observed, which implies that the equilibrium point was greater than

TABLE 4. The effect of increasing presowing densities of Pratylenchus thornei on grain yield ${ }^{\mathrm{a}}$

\begin{tabular}{lccc}
\hline $\begin{array}{l}\text { Experimental year } \\
\text { cultivar and } \\
\text { experimental year }\end{array}$ & $\begin{array}{c}\text { Rate of } \\
\text { change (slope) }\end{array}$ & $\begin{array}{c}P \text { value } \\
\text { (rate of change) }\end{array}$ & $\begin{array}{c}\text { Yield } \\
\text { potential }^{\mathrm{b}}\end{array}$ \\
\hline $\begin{array}{c}\text { Catalina } \\
2011\end{array}$ & 0.028 & 0.626 & 3.76 \\
2012 & 0.111 & 0.055 & 1.72 \\
2013 & 0.116 & $\mathbf{0 . 0 4 4}$ & 2.41 \\
2014 & 0.062 & $\mathbf{0 . 0 0 7}$ & 0.45 \\
Chara & & & \\
2011 & -0.017 & 0.719 & 4.35 \\
2012 & 0.060 & 0.363 & 2.35 \\
2013 & 0.213 & $\mathbf{0 . 0 0 2}$ & 1.87 \\
2014 & 0.049 & $\mathbf{0 . 0 1 8}$ & 0.40 \\
Hindmarsh & & & \\
2011 & 0.071 & 0.214 & 4.54 \\
2012 & 0.029 & 0.681 & 4.19 \\
2013 & 0.099 & 0.057 & 3.87 \\
2014 & 0.099 & $\mathbf{0 . 0 0 0}$ & 0.95 \\
Derrimut & & & \\
2011 & -0.207 & $\mathbf{0 . 0 0 0}$ & 4.08 \\
2012 & -0.187 & $\mathbf{0 . 0 0 1}$ & 3.36 \\
2013 & 0.078 & 0.136 & 2.53 \\
2014 & 0.002 & 0.943 & 0.86 \\
Yitpi & & & 4.28 \\
2011 & -0.215 & $\mathbf{0 . 0 0 0}$ & 2.83 \\
2012 & 0.101 & 0.137 & 0.79 \\
2013 & 0.002 & 0.913 & \\
2014 & & & \\
\hline
\end{tabular}

a The slope [(tons hectare $\left.{ }^{-1}\right)\left(\ln \text { initial } P \text {. thornei grams of soil }{ }^{-1}\right)^{-1}$ ], constant (yield potential; tons hectare ${ }^{-1}$ ), and significance of the relationship are presented for each of the five experimental cereal cultivars for each year between 2011 and 2014 at Banyena, Victoria.

b The yield potential (tons hectare ${ }^{-1}$ ) provides a prediction of the yield potential in the absence of $P$. thornei, but it should be used with caution because no presowing nematode densities were zero. The yield potential was significantly different from zero $(P<0.001)$ of each experimental year cultivar in each experiment.

c Bold text indicates a rate of slope change significantly $(P<0.05)$ different from zero. 
for the other cultivars Catalina, Hindmarsh, and Chara where the equilibrium point could be estimated. A graphical representation of regression solutions from the 2013 experiment data is presented (Fig. 4), highlighting distinct differences in the relationship between presowing and postharvest $P$. thornei densities for the cultivars evaluated, with the cultivars Catalina, Hindmarsh, and Chara having a significantly decreased $\hat{\alpha}$ estimate compared with the cultivars Derrimut and Yitpi. The results show that cultivars Derrimut and Yitpi have not reached the equilibrium point within the range of observed experimental data.

The relationship between presowing and postharvest nematode densities shows that the multiplication rate decreased as the presowing nematode densities increased (Figs. 3 and 4). The results in Figure 3 demonstrate how the change in multiplication rate varied between experimental years, and those in Figure 4 show the variation between cultivars in a single experimental year.

\section{DISCUSSION}

We used a unique approach to assess the relationship between presowing densities of $P$. thornei and grain yield or nematode multiplication rates. The relationship between the natural log of presowing $P$. thornei densities determined using a DNA-based soil test (PREDICTAB) and grain yield was found to be linear for each of the cultivars in each of the seasons within the study. The effect of season was found to be a major driver in determining the extent of the yield losses measured, with grain yield losses observed in only two of the five cultivars and in only two of the four seasons. Analysis of $P$. thornei multiplication data demonstrated that an increase in presowing nematode densities resulted in a decreased nematode multiplication rate in all seasons in all cultivars, despite variation between seasons. In the susceptible cultivars Derrimut and Yitpi, an equilibrium point could only be calculated in one of the four experimental years, demonstrating the ability of these cultivars to support increased densities of $P$. thornei to high levels in the field.

Validity of study. Unlike previous studies (Nicol et al. 1999; Smiley and Machado 2009), this study relied on wheat to establish a range of presowing $P$. thornei densities. The use of similar crop types ensured that the setup year cultivars did not result in other pathogen changes within the soil, with soil testing and inspection of plant roots conducted with each experiment to confirm that no other soilborne pathogens of importance were detected.

TABLE 5. Predicted grain yield (tons hectare ${ }^{-1}$ ) and percentage yield loss (shown in parentheses) in the experimental cereal cultivar Derrimut during 2011 and 2012 and cultivar Yitpi during 2011 at a range of presowing nematode densities (Pratylenchus thornei grams of soil ${ }^{-1}$ ) using the equations presented in Table 4

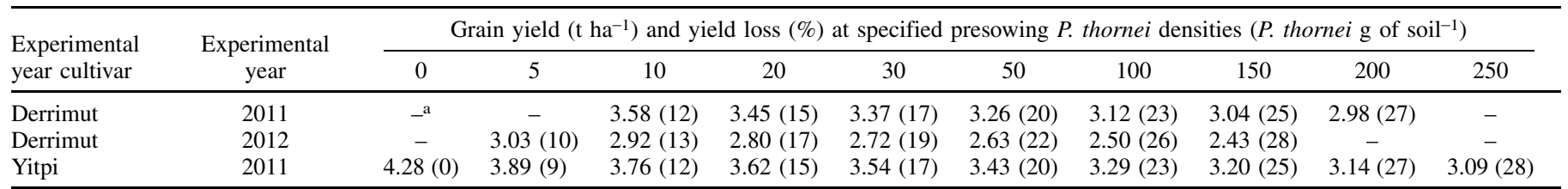

a These presowing nematode densities are not presented because they are outside the range of observed experimental data.

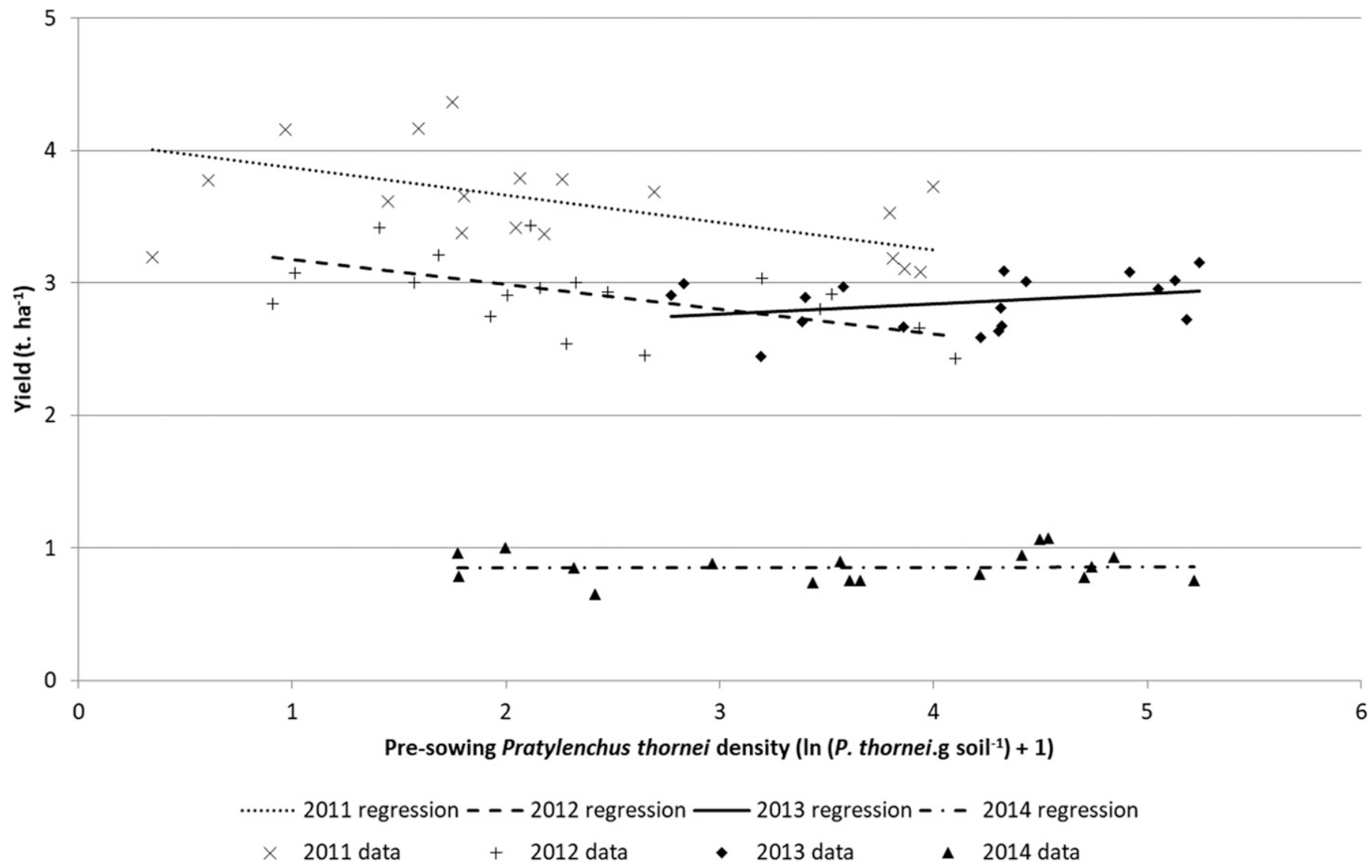

Fig. 2. The effect of increasing presowing Pratylenchus thornei density $\left[\ln \left(P\right.\right.$. thornei grams of $\left.\left.\operatorname{soil}^{-1}+1\right)\right]$ on grain yield (tons hectare $\left.{ }^{-1}\right)$ for the wheat cultivar Derrimut grown at Banyena, Victoria from 2011 to 2014. 
A range of presowing nematode densities was established in each of the experimental years rather than two distinct strata of presowing nematode densities corresponding with the setup year cultivars. Conducting the experiments over several seasons highlighted differences between the maximum and minimum presowing nematode densities, with presowing nematode densities for each cultivar in each experimental year being different. Despite these differences, the relationships between the presowing $P$. thornei densities and grain yield loss or final nematode densities could be estimated robustly.

Grain yield losses. Yield losses were observed in the experimental year cultivars Derrimut and Yitpi during 2011 and only in Derrimut during 2012, with the maximum yield losses observed estimated to be 27,28 , and $28 \%$, respectively. These yield losses are similar to the $27 \%$ yield loss reported for the cultivar Machete in South Australia by Nicol et al. (1999). Nicol et al. (1999) also reported higher yield losses of $38 \%$ for the cultivar Spear. Eastwood et al. (1994) examined yield losses caused by $P$. thornei in four locations across Victoria during 1993, with losses in the cultivar Meering varying from 0 to $44 \%$, demonstrating the potential range of losses that can be observed in one season for one cultivar. Interestingly, the yield losses observed by Eastwood et al. (1994) and Nicol et al. (1999) were at significantly lower $P i$ values than this study, with the maximum $P i$ values observed being 15.5 and $22.0 P$. thornei $\mathrm{g}$ of soil $^{-1}$, respectively. We used a DNA-based soil test for nematode quantification, whereas the earlier two studies both used a manual extraction technique, which could account for lower nematode densities observed. In Queensland, grain yield losses varied between 26 and 76\%, with $P i$ values of 8.1 and 3.5 P. thornei $\mathrm{g}$ of soil $^{-1}$, respectively, which is consistent with the higher yield losses reported in northern Australia (Owen et al. 2014; Reen et al. 2014).
Yield losses reported internationally along with the variability in yield losses between seasons are consistent with those reported in this study, although at lower P. thornei densities than in this study (Ortiz-Monasterio and Nicol 2004; Smiley 2009). This may be a consequence of the different nematode quantification techniques or may suggest that a threshold level exists, whereby no further yield losses are incurred past a particular nematode density. Alternatively, these differences in yield losses could be because of a number of other factors, including but not limited to a changing farming system, location, soil type, and rainfall, which have previously been reported to affect nematode multiplication and may, therefore, also

TABLE 6. The minimum and maximum presowing $(P i)$ and postharvest $(P f)$ densities of Pratylenchus thornei ( $P$. thornei grams of soil ${ }^{-1}$ ) in the experimental year of each experiment for each experimental year cultivar

\begin{tabular}{lcccc}
\hline \multirow{2}{*}{$\begin{array}{l}\text { Time of density } \\
\text { measurement and } \\
\text { experimental year } \\
\text { cultivar }\end{array}$} & \multicolumn{5}{c}{ Experimental year } \\
\cline { 2 - 5 } & 2011 & 2012 & 2013 & 2014 \\
\hline$P i$ density (range) & & & & \\
$\quad$ Catalina & $1.7-90.2$ & $2.0-76.8$ & $19.0-182.0$ & $3.2-133$ \\
$\quad$ Chara & $0.7-77.0$ & $2.5-33.2$ & $20.0-167.0$ & $4-197.1$ \\
Hindmarsh & $2.6-136.8$ & $3.2-44.8$ & $12.0-163.0$ & $4.1-151.3$ \\
Derrimut & $0.4-53.6$ & $1.5-59.6$ & $15.0-188.4$ & $4.9-184.2$ \\
$\quad$ Yitpi & $0.3-139.8$ & $2.6-37.6$ & $12.0-171.0$ & $5.8-288.6$ \\
$P f$ density (range) & & & & \\
$\quad$ Catalina & $4.4-51.9$ & $5.6-27.5$ & $19.3-67.6$ & $3.7-44.5$ \\
$\quad$ Chara & $6.1-83.8$ & $6.5-66.3$ & $21.2-86.2$ & $2.1-64.4$ \\
$\quad$ Hindmarsh & $3.2-81.2$ & $3.1-45.0$ & $14.8-80.2$ & $3.2-41.3$ \\
$\quad$ Derrimut & $11.4-218.1$ & $9.6-178.1$ & $83.3-229.7$ & $10.5-113$ \\
$\quad$ Yitpi & $18.1-259.6$ & $19.0-129.2$ & $56.0-263.8$ & $6.8-109.9$ \\
\hline
\end{tabular}

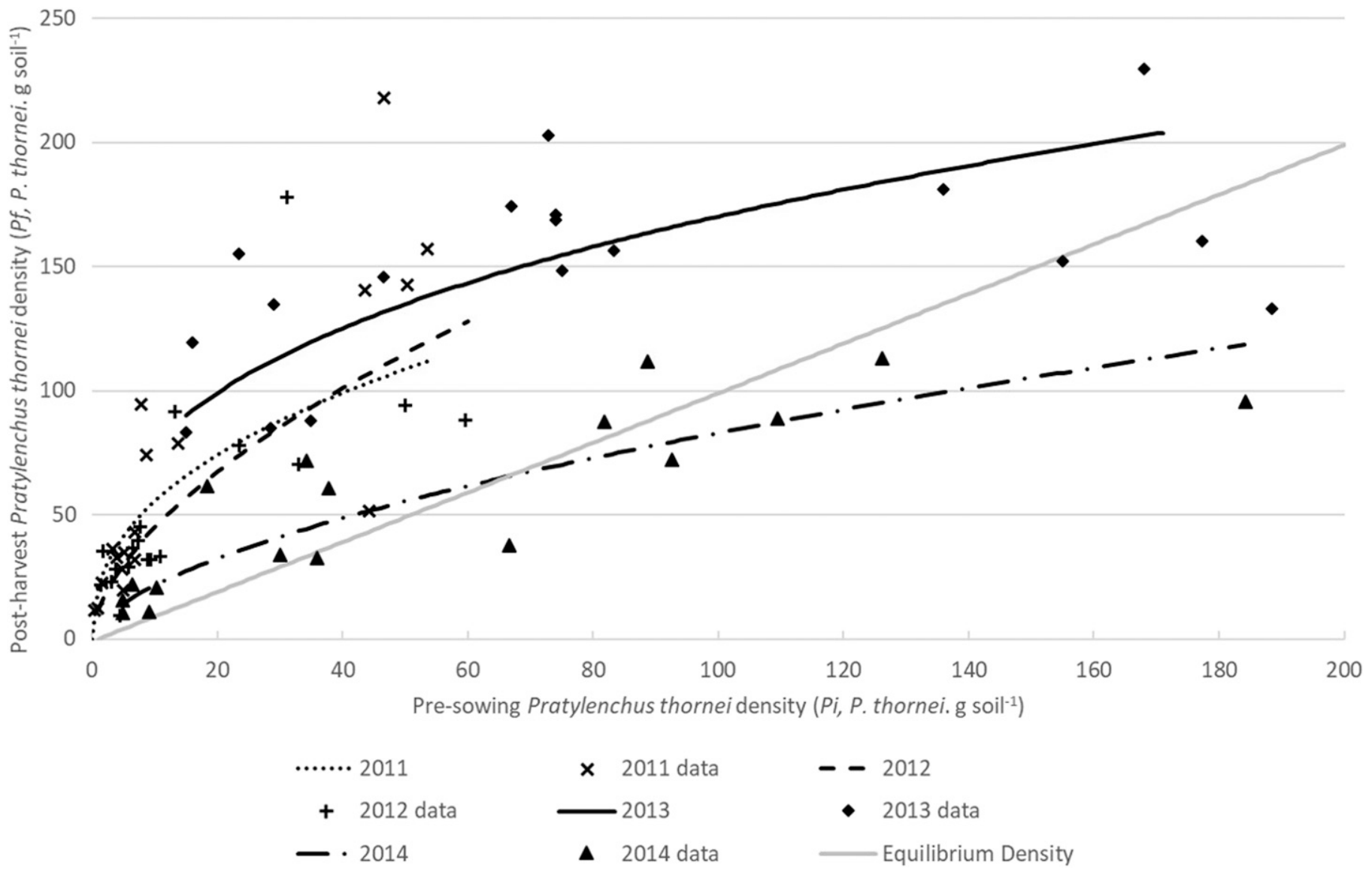

Fig. 3. The relationship between presowing $(P i)$ and postharvest $(P f)$ Pratylenchus thornei densities $\left(P\right.$. thornei grams of soil $\left.{ }^{-1}\right)$ in the wheat cultivar Derrimut from 2011 to 2014 at Banyena, Victoria. The equilibrium line $(P i=P f)$ is indicated to show when the nematode multiplication rate $(P f / P i)$ is equal to one. 
affect yield losses (Cadet et al. 2004; Castillo et al. 1995; Fanning et al. 2018; Farsi et al. 1995; Govaerts et al. 2006; Kincaid 1946; Thompson et al. 2015a).

Grain yield losses were measured in only two of the four experimental years in the experimental year cultivar Derrimut and only one of the four experimental years in the experimental year cultivar Yitpi. Few studies have repeatedly assessed grain yield loss caused by $P$. thornei over consecutive years. To the best of our knowledge, Ortiz-Monasterio and Nicol (2004) and Smiley (2009) are the only others to measure grain yield losses and the variation between years or seasons. Smiley (2009) used a nematicide to establish high and low nematode densities, with 23 and $40 \%$ yield losses measured between 2 years in one cultivar, and in other experiments, Smiley (2009) measured from 9 to $29 \%$ and from 6 to $15 \%$ yield losses within 3 years at two different locations. OrtizMonasterio and Nicol (2004) observed yield losses in 2 consecutive years varying between 12 and $37 \%$ but only in plots that had reduced irrigation compared with in another experimental year when they observed no yield differences between treatments when using a full irrigation system. The results of this study together with those of Ortiz-Monasterio and Nicol (2004) and Smiley (2009) highlight the importance of conducting yield loss experiments over multiple years in the same location because the yield losses caused by $P$. thornei seem highly variable across years.

No yield losses caused by $P$. thornei were observed in the three cultivars Catalina, Chara, and Hindmarsh. Unexpectedly, these cultivars demonstrated a significant positive relationship between presowing $P$. thornei densities and grain yield, resulting in increased grain yield as nematode densities increased in some seasons. Supplementary data collected from the experiments did not provide a definitive explanation of these yield increases. However, through observation of the experiments during crop maturity, it was evident

TABLE 7. The estimates of $\alpha$ and $\beta$ values for the regression solution used to determine the postharvest density of Pratylenchus thornei [postharvest nematode density $\left(P\right.$. thornei grams of $\left.\operatorname{soil}^{-1} ; P f\right)=e^{\alpha} \times$ presowing nematode density $\left.\left(P i^{\beta}\right)\right]^{\mathrm{a}}$

\begin{tabular}{lccccc}
\hline $\begin{array}{l}\text { Experimental cultivar and } \\
\text { experimental year }\end{array}$ & $\hat{\alpha}$ & $\begin{array}{c}\text { SE } \\
(\hat{\alpha})\end{array}$ & $\hat{\beta}$ & $\begin{array}{c}\text { SE } \\
(\hat{\beta})\end{array}$ & $\begin{array}{c}\text { Equilibrium } \\
\text { point }(\widehat{E Q})\end{array}$ \\
\hline Catalina & & & & & \\
2011 & 2.13 & 0.156 & 0.297 & 0.051 & 20.7 \\
2012 & 1.30 & 0.133 & 0.461 & 0.043 & 11.1 \\
2013 & 2.64 & 0.252 & 0.214 & 0.059 & 28.7 \\
2014 & 1.10 & 0.175 & 0.461 & 0.043 & 7.7 \\
Chara & & & & & \\
2011 & 2.00 & 0.134 & 0.419 & 0.037 & 31.3 \\
2012 & 1.35 & 0.109 & 0.584 & 0.029 & 25.7 \\
2013 & 2.36 & 0.220 & 0.336 & 0.049 & 35 \\
2014 & 0.70 & 0.141 & 0.584 & 0.029 & 5.4 \\
Hindmarsh & & & & & \\
2011 & 1.71 & 0.177 & 0.615 & 0.052 & 84.9 \\
2012 & 0.81 & 0.135 & 0.779 & 0.045 & 39.1 \\
2013 & 1.48 & 0.244 & 0.532 & 0.058 & 23.6 \\
2014 & -0.11 & 0.180 & 0.779 & 0.045 & 0.6 \\
Derrimut & & & & & \\
2011 & 3.05 & 0.137 & 0.419 & 0.037 & NA \\
2012 & 2.46 & 0.106 & 0.584 & 0.029 & NA \\
2013 & 3.59 & 0.215 & 0.336 & 0.049 & NA \\
2014 & 1.73 & 0.145 & 0.584 & 0.029 & 64 \\
Yitpi & & & & & \\
2011 & 3.44 & 0.133 & 0.419 & 0.037 & NA \\
2012 & 2.52 & 0.106 & 0.584 & 0.029 & NA \\
2013 & 3.51 & 0.210 & 0.336 & 0.049 & NA \\
2014 & 1.38 & 0.146 & 0.584 & 0.029 & 27.6 \\
\hline
\end{tabular}

a The standard errors (SEs) associated with each of the parameter estimates for each experimental year cultivar in each experimental year are also presented. Based on these parameter estimates, the equilibrium point $(P f=P i)$ was estimated for each experimental year cultivar in each experimental year.

b NA means that the equilibrium point is outside the range of data in the experimental year. that field plots with higher nematode densities remained greener for longer and may have been able to capitalize on later rainfall compared with plots with lower nematode densities, which matured slightly earlier. These results highlight the inherent dangers in extending the yield loss knowledge to growers and advisors without providing the variation between years and cultivars. The differences in the degree of yield losses measured between experimental year cultivars within this study highlight the variation in tolerance between cultivars and the importance of screening for tolerance to nematodes. If tolerant cultivars that do not display yield losses when planted in high nematode densities can be identified, there would be less reliance on nematode resistance and reducing nematode densities.

Cultivar resistance. The relationship between the presowing $(P i)$ and postharvest $(P f) P$. thornei density demonstrated that, as the $P i$ increased, the $P$. thornei multiplication rate $(P f / P i)$ decreased in all experimental year cultivars in all experimental years. This relationship has been reported by Ferris (1985) and Ortiz-Monasterio and Nicol (2004) for M. incognita and P. thornei, respectively. Ferris (1985) suggested that the resource availability for nematodes is decreased at higher nematode densities, and therefore, there is a decreased multiplication rate at higher $P i$ values. In contrast to these studies, an earlier study by Nicol et al. (1999) reported that the cultivar Warigal, susceptible to $P$. thornei, displayed a quadratic relationship compared with the resistant cultivars, which displayed a linear relationship. However, their study had limited data at higher $P i$ values, which may have affected the relationships reported. We found that the relationship between $P i$ and $P f$ was similar for all cultivars, which has management implications. The cultivation of resistant cultivars is an effective method to control P. thornei (Fanning et al. 2018), and the relationship reported here indicates that it will be difficult to reduce nematode densities at lower $P i$ values. These relationships further highlight the importance of regularly screening cultivars to ensure that the resistance is known to prevent these increases in nematode numbers.

The equilibrium point, defined as the value of $P i$ at which $P f$ and $P i$ are equal, could be calculated for the susceptible cultivars Derrimut and Yitpi in only 1 of the 4 experimental years. This was a result of the putative equilibrium point being above the maximum $P i$ for the other 3 experimental years, with the experimental year that the equilibrium point could be estimated for coinciding with the lowest rainfall and grain yields. In comparison, an equilibrium point could be estimated in all years for the moderately resistant cultivars, having lower equilibrium points than the susceptible cultivars as expected. Previously, Nicol et al. (1999) compared the relationship between $P i$ and $P f$ for $P$. thornei in relation to the equilibrium point for the cereal line cultivars GS50a (resistant) and AUS4930 (resistant) versus Warigal (susceptible). The equilibrium points reported by Nicol et al. (1999) were 8.9, 9.2, and 60.0 P. thornei $\mathrm{g}$ of soil ${ }^{-1}$ for genotypes GS50a, AUS4930, and Warigal, respectively. These equilibrium points are significantly lower than those estimated in our study. However, similar to our study, the resistant cultivars had significantly lower equilibrium points when compared with susceptible cultivars. These results show that, irrespective of season, susceptible cultivars have the ability to support significantly higher nematode densities.

Nematode multiplication varied across seasons. Few studies have carried out similar experiments over several seasons in field conditions. Previously, Seinhorst (1967) reported that multiplication rates varied between years in Pratylenchus crenatus, and Fanning et al. (2018) reported multiplication rates variation between years in Pratylenchus neglectus and P. thornei. This variation is as expected with nematode multiplication rates previously reported to be affected by changes in rainfall, soil temperature, $\mathrm{pH}$, moisture, and nutrition (Cadet et al. 2004; Castillo et al. 1995, 1996; Kincaid 1946; Mai and Kable 1968; Mizukubo and Adachi 1997; Thompson et al. 2015b). The changes in multiplication rate reported here and previously are important from 
a management perspective. Growers will need to measure nematode densities regularly because the multiplication rates will change depending on the season; additionally, a resistant cultivar may not be reducing nematode densities, or a susceptible cultivar may not be increasing nematode densities to the extent expected. Unfortunately, it means that a prediction of final $P$. thornei densities based on a presowing nematode density and cultivar resistance cannot be achieved with these results. However, the trends estimated from this study can enable the determination of when nematode testing will be most beneficial in fields.

Methods used and comparison with other methodsimprovements. Historically, the study of yield losses owing to root lesion nematodes has primarily been conducted with the use of nematicides or fumigation (Doyle et al. 1987; Eastwood et al. 1994; Smiley 2009; Smiley et al. 2014; Taylor and McKay 1993; Taylor et al. 1999; Thompson et al. 1993, 1995, 2012). However, numerous issues surrounding the use of these treatments have been reported, including limited efficacy and toxicity. Eastwood et al. (1994) suggested that the nematicide aldicarb only reduced $P$. thornei densities down to $30 \mathrm{~cm}$, but $>50 \%$ of $P$. thornei are found deeper than $30 \mathrm{~cm}$, suggesting only partial control of nematodes through the soil profile. Fumigation has also been reported to cause toxicity in plants, making quantifying yield losses difficult because of the confounding effect of the treatment (Jones 1968; Nicol et al. 1999). Nematicides have high toxicity to mammals, and they are difficult to apply, resulting in resistant cultivars being adopted by growers for nematode control. Currently, there are no nematicides registered for use in cereal crops in Australia (Vanstone et al. 2008).

With the complexities inherent in nematicide research, other methods of quantifying yield losses have been adopted. Nicol et al.
(1999) used a range of crop types (linseed [Linum usitatissimum], canola [Brassica napus], barley, oat [Avena sativa], and wheat) and fallow to establish presowing nematode densities and related these to grain yield loss through regression. The same method of regression was used by Owen et al. (2014) and Reen et al. (2014), who also planted a range of crops to establish presowing nematode densities over a number of seasons. Although Nicol et al. (1999) reported that there was no indication that they affected grain yield, using different crop types could result in differences in soil moisture and nitrogen, which also affect grain yields (Angus et al. 2015; Armstrong et al. 2019; Hannah and O'Leary 1995). We overcame these potential issues by planting different wheat cultivars with contrasting resistance and susceptibility, thus reducing any potential soil moisture and nitrogen differences.

The designs still induced a range of minimum and maximum presowing nematode densities across the setup year cultivars, meaning that the range of presowing nematode densities for each experimental year cultivar was different. The range of presowing nematode densities meant that the regression relationship between presowing $P$. thornei densities and grain yield could be determined and provides an ideal approach for determining yield losses caused by root lesion nematodes (Table 7). Further research is required to understand the effects of environment before growers can predict yield losses in a given season. However, currently this method allows growers to predict a range of potential yield losses at presowing nematode densities in their fields, allowing them to make informed decisions around the presowing $P$. thornei densities in which they will start control methods to prevent further grain yield losses.

Conclusion. The relationship between presowing $P$. thornei densities, determined through a DNA-based soil test (PREDICTAB), and grain yield was established for a set of commercial wheat

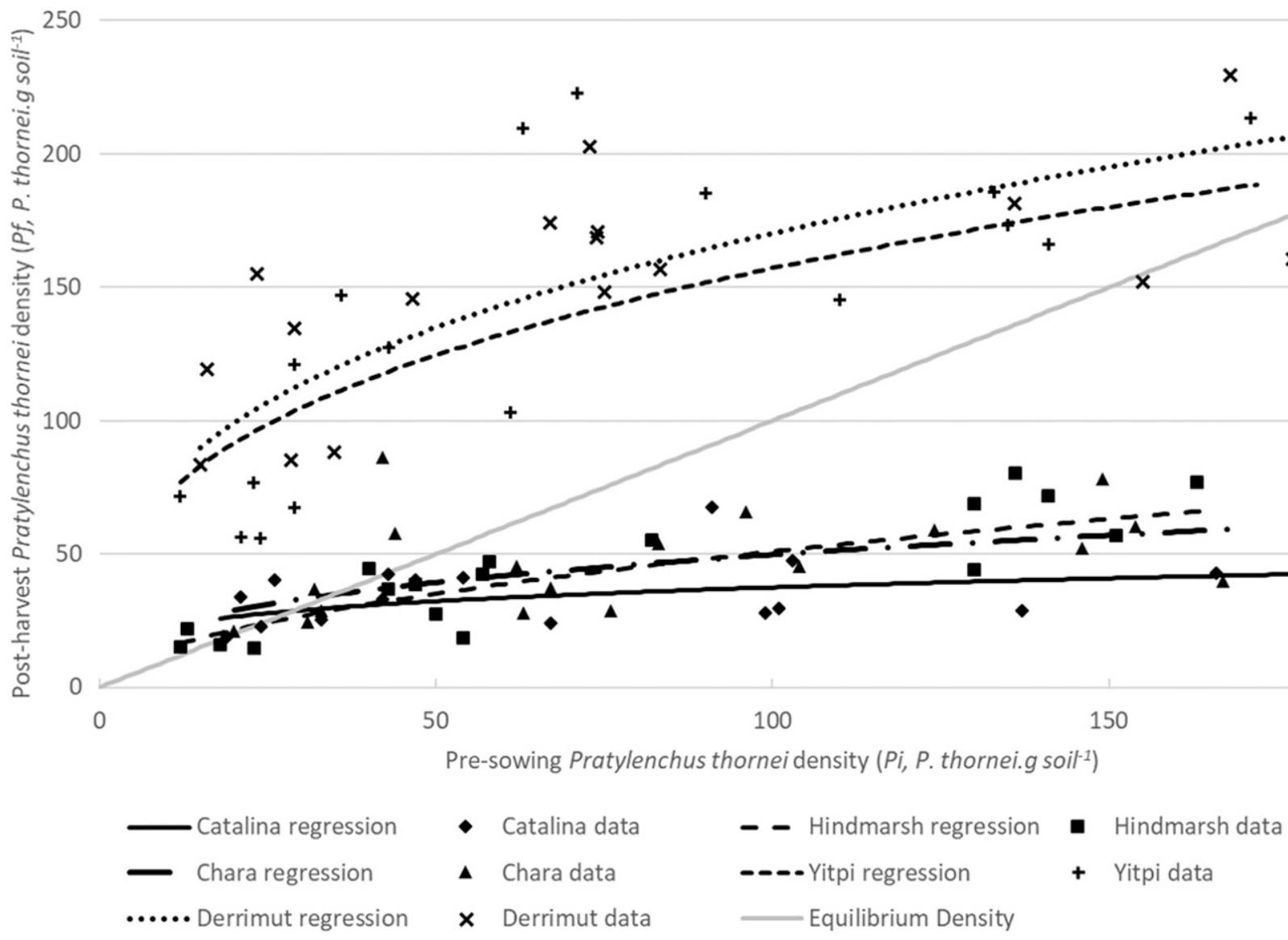

Fig. 4. The relationship between presowing (Pi) and postharvest (Pf) Pratylenchus thornei densities (P. thornei grams of soil $\left.{ }^{-1}\right)$ for the cereal cultivars Catalina, Hindmarsh, Chara, Yitpi, and Derrimut during the 2013 experimental year at Banyena, Victoria. The equilibrium line $(P i=P f)$ is indicated to show when the nematode multiplication rate $(P f / P i)$ is equal to one. 
and barley cultivars. A linear relationship was observed between the natural $\log$ of the presowing $P$. thornei density and grain yield across all seasons. Grain yield losses varied between cultivars and seasons, with the greatest yield losses observed ( 25 to $28 \%$ ) during 2011 and 2012. Although these results cannot be used to definitively estimate yield losses in a given season, they do indicate potential risk of yield loss from a given presowing nematode density. Further research is required to define the seasonal effects on grain yield loss.

The relationship between presowing and postharvest $P$. thornei densities was determined, demonstrating that increasing presowing nematode densities resulted in decreased multiplication rates in all seasons and in all cultivars. Although multiplication varied from one season to the next, making it difficult to predict postharvest nematode densities, there was consistent ranking of cultivars based on their known resistance/susceptibility rating. These results emphasize that growers need to measure nematode densities regularly because multiplication rates will change depending on the season; cultivars may not be increasing or decreasing nematode densities to the extent expected.

\section{ACKNOWLEDGMENTS}

The experiments were made possible with the technical assistance of Graham Exell, Jordan McDonald, Ashley Perdue, Seona Casonato, and Luise Sigel. We thank Adrian Drum for provision of land. We also acknowledge Dr. Jacky Edwards for providing comment on the manuscript.

\section{LITERATURE CITED}

Angus, J. F., Kirkegaard, J. A., Hunt, J. R., Ryan, M. H., Ohlander, L., and Peoples, M. B. 2015. Break crops and rotations for wheat. Crop Pasture Sci. 66:523-552.

Armstrong, R. D., Perris, R., Munn, M., Dunsford, K., Robertson, F., Hollaway, G. J., and O'Leary, G. J. 2019. Effects of long-term rotation and tillage practice on grain yield and protein of wheat and soil fertility on a vertosol in a medium-rainfall temperate environment. Crop Pasture Sci. 70:1-15.

Ballard, R. A., Hutton, R. E., Taylor, S. P., McKay, A. C., and Howie, J. H. 2006. Field resistance of annual pasture legumes to the root lesion nematode, Pratylenchus neglectus. Aust. Plant Pathol. 35:303-308.

Butler, D. G., Cullis, B. R., Gilmour, A. R., and Gogel, B. J. 2009. ASReml-R Reference Manual, Version 3. Queensland Department of Primary Industries and Fisheries, NSW Department of Primary Industries, Brisbane, Australia.

Cadet, P., Berry, S., and Spaull, V. 2004. Mapping of interactions between soil factors and nematodes. Eur. J. Soil Biol. 40:77-86.

Castillo, P., Trapero-Casas, J. L., and Jiménez-Díaz, R. M. 1995. Effect of time, temperature, and inoculum density on reproduction of Pratylenchus thornei in carrot disk cultures. J. Nematol. 27:120-124.

Castillo, P., Trapero-Casas, J. L., and Jimenez-Diaz, R. M. 1996. The effect of temperature on hatching and penetration of chickpea roots by Pratylenchus thornei. Plant Pathol. 45:310-315

Cook, R., and Evans, K. 1987. Resistance and tolerance. Pages 179-231 in: Principles and Practice of Nematode Control in Crops. R. H. Brown and B. R. Kerry, eds. Academic Press, London, United Kingdom.

Dababat, A., Mokrini, F., Laasli, S.-E., Orakci, G., Duman, N., and İmren, M. 2019. Host suitability of different wheat lines to Pratylenchus thornei under naturally infested field conditions in Turkey.

Doyle, A. D., McLeod, R. W., Wong, P. T. W., Hetherington, S. E., and Southwell, R. J. 1987. Evidence for the involvement of the root lesion nematode Pratylenchus thornei in wheat yield decline in northern New South Wales. Aust. J. Exp. Agric. 27:563-570.

Eastwood, R. F., Smith, A., and Wilson, J. 1994. Pratylenchus thornei is causing yield losses in Victorian wheat crops. Australas. Nematol. Newsl. 5: 10-13.

Fanning, J., Linsell, K., McKay, A., Gogel, B., Munoz Santa, I., Davey, R., and Hollaway, G. 2018. Resistance to the root lesion nematodes Pratylenchus thornei and P. neglectus in cereals: Improved assessments in the field. Appl. Soil Ecol. 132:146-154.

Farsi, M., Vanstone, V. A., Fisher, J. M., and Rathjen, A. J. 1995. Genetic variation in resistance to Pratylenchus neglectus in wheat and triticales. Aust. J. Exp. Agric. 35:597-602.

Ferris, H. 1985. Density-dependent nematode seasonal multiplication rates and overwinter survivorship: A critical point model. J. Nematol. 17:93-99.

Gilmour, A. R., Cullis, B. R., and Verbyla, A. 1997. Accounting for natural and extraneous variation in the analysis of field experiments. J. Agric. Biol. Environ. Stat. 2:269-293.
Govaerts, B., Mezzalama, M., Sayre, K. D., Crossa, J., Nicol, J. M., and Deckers, J. 2006. Long-term consequences of tillage, residue management, and crop rotation on maize/wheat root rot and nematode populations in subtropical highlands. Appl. Soil Ecol. 32:305-315.

Hannah, M., and O'Leary, G. 1995. Wheat yield response to rainfall in a longterm multi-rotation experiment in the Victorian Wimmera. Aust. J. Exp. Agric. 35:951-960.

Hollaway, C. J., Taylor, S. P., Eastwood, R. F., and Hunt, C. H. 2000. Effect of field crops on density of Pratylenchus in southeastern Australia. Part 2. P. thornei. J. Nematol. 32:600-608.

Hollaway, G. J. 2002. Effect of oat (Avena sativa) on the population density of Pratylenchus thornei in the field. Aust. Plant Pathol. 31:147-149.

Jones, F. G. W. 1968. Pages 164-166 in: Root lesion nematodes. Report of the Rothamsted Experimental Station.

Keil, T., Laubach, E., Sharma, S., and Jung, C. 2009. Screening for resistance in the primary and secondary gene pool of barley against the root-lesion nematode Pratylenchus neglectus. Plant Breed. 128:436-442.

Kenter, C., Lukashyk, P., Daub, M., and Ladewig, E. 2014. Population dynamics of Heterodera schachtii Schm. and yield response of susceptible and resistant sugar beet (Beta vulgaris L.) after cultivation of susceptible and resistant oilseed radish (Raphanus sativus L.). J. Kultpflanzen 66:289-299.

Kincaid, R. R. 1946. Soil factors affecting incidence of root knot. Soil Sci. 61: 101-109.

Mai, W. F., and Kable, P. F. 1968. Influence of soil moisture on Pratylenchus penetrans. Nematologica 14:101-122.

Mills, W. D., and Sheppard, J. A. 1998. Wheat Varieties of Queensland. Queensland Department of Primary Industries.

Mizukubo, T., and Adachi, H. 1997. Effect of temperature on Pratylenchus penetrans development. J. Nematol. 29:306-314.

Moens, M., and Perry, R. N. 2009. Migratory plant endoparasitic nematodes: A group rich in contrasts and divergence. Annu. Rev. Phytopathol. 47:313-332.

Mokrini, F., Viaene, N., Waeyenberge, L., Dababat, A. A., and Moens, M. 2018. Investigation of resistance to Pratylenchus penetrans and P. thornei in international wheat lines and its durability when inoculated together with the cereal cyst nematode Heterodera avenae, using $\mathrm{qPCR}$ for nematode quantification. Eur. J. Plant Pathol. 151:875-889.

Mokrini, F., Waeyenberge, L., Viaene, N., Andaloussi, F. A., and Moens, M. 2016. Diversity of root-lesion nematodes (Pratylenchus spp.) associated with wheat (Triticum aestivum and T. durum) in Morocco. Nematology 18: 781-801.

Murray, G. M., and Brennan, J. P. 2009. Estimating disease losses to the Australian wheat industry. Aust. Plant Pathol. 38:558-570.

Murray, G. M., and Brennan, J. P. 2010. Estimating disease losses to the Australian barley industry. Aust. Plant Pathol. 39:85-96.

Nicol, J. M., Davies, K. A., Hancock, T. W., and Fisher, J. M. 1999. Yield loss caused by Pratylenchus thornei on wheat in South Australia. J. Nematol. 31:367-376.

Ophel-Keller, K., McKay, A., Hartley, D., and Herdina, J. C. 2008. Development of a routine DNA-based testing service for soilborne diseases in Australia. Aust. Plant Pathol. 37:243-253.

Ortiz-Monasterio, I., and Nicol, J. M. 2004. Effects of the root-lesion nematode, Pratylenchus thornei, on wheat yields in Mexico. Nematology 6:485-493.

Owen, K. J., Clewett, T. G., Bell, K. L., and Thompson, J. P. 2014. Wheat biomass and yield increased when populations of the root-lesion nematode (Pratylenchus thornei) were reduced through sequential rotation of partially resistant winter and summer crops. Crop Pasture Sci. 65:227-241.

Patterson, H. D., and Thompson, R. 1971. Recovery of inter-block information when block sizes are unequal. Biometrika 58:545-554.

Queensland Government. 2019. SILO Climate Data. https://www.longpaddock. qld.gov.au/silo/

R Core Team. 2019. R: A Language and Environment for Statistical Computing. R Foundation for Statistical Computing, Vienna, Austria.

Reen, R. A., Thompson, J. P., Clewett, T. G., Sheedy, J. G., and Bell, K. L. 2014. Yield response in chickpea cultivars and wheat following crop rotations affecting population densities of Pratylenchus thornei and arbuscular mycorrhizal fungi. Crop Pasture Sci. 65:428-441.

Rodda, M. S., Hobson, K. B., Forknall, C. R., Daniel, R. P., Fanning, J. P., Pounsett, D. D., Simpfendorfer, S., Moore, K. J., Owen, K. J., Sheedy, J. G., Thompson, J. P., Hollaway, G. J., and Slater, A. T. 2016. Highly heritable resistance to root-lesion nematode (Pratylenchus thornei) in Australian chickpea germplasm observed using an optimised glasshouse method and multi-environment trial analysis. Aust. Plant Pathol. 45:309-319.

Schmidt, A. L., McIntyre, C. L., Thompson, J., Seymour, N. P., and Liu, C. J. 2005. Quantitative trait loci for root lesion nematode (Pratylenchus thornei) resistance in Middle-Eastern landraces and their potential for introgression into Australian bread wheat. Aust. J. Agric. Res. 56:1059-1068.

Schmidt, K., Sikora, R. A., and Richter, O. 1993. Modelling the population dynamics of the sugar beet cyst nematode Heterodera schachtii. Crop Prot. $12: 490-496$. 
Seinhorst, J. W. 1965. The relation between nematode density and damage to plants. Nematologica 11:137-154.

Seinhorst, J. W. 1967. The relationships between population increase and population density in plant parasitic nematodes. Nematologica 13:429-442.

Seinhorst, J. W. 1972. The relationship between yield and square root of nematode density. Nematologica 18:585-590.

Sheedy, J. G., McKay, A. C., Lewis, J., Vanstone, V. A., Fletcher, S., Kelly, A., and Thompson, J. P. 2015. Cereal cultivars can be ranked consistently for resistance to root-lesion nematodes (Pratylenchus thornei \& P. neglectus) using diverse procedures. Aust. Plant Pathol. 44:175-182.

Sheedy, J. G., and Thompson, J. P. 2009. Resistance to the root-lesion nematode Pratylenchus thornei of Iranian landrace wheat. Aust. Plant Pathol. 38:478-489.

Smiley, R. W. 2009. Root-lesion nematodes reduce yield of intolerant wheat and barley. Agron. J. 101:1322-1335.

Smiley, R. W., Gourlie, J. A., Yan, G., and Rhinhart, K. E. L. 2014. Resistance and tolerance of landrace wheat in fields infested with Pratylenchus neglectus and P. thornei. Plant Dis. 98:797-805.

Smiley, R. W., and Machado, S. 2009. Pratylenchus neglectus reduces yield of winter wheat in dryland cropping systems. Plant Dis. 93:263-271.

Smiley, R. W., Whittaker, R. G., Gourlie, J. A., and Easley, S. A. 2005. Suppression of wheat growth and yield by Pratylenchus neglectus in the Pacific Northwest. Plant Dis. 89:958-968.

Taylor, S. P., Hollaway, G. J., and Hunt, C. H. 2000. Effect of field crops on population densities of Pratylenchus neglectus and P. thornei in southeastern Australia. Part 1. P. neglectus. J. Nematol. 32:591-599.

Taylor, S. P., and McKay, A. 1993. Assessing yield loss caused by Pratylenchus thornei and P. neglectus in South Australia. Ninth Biennial Australasian Plant Pathology Conference 4th-8th July 1993. Hobart, Tasmania, Australia.

Taylor, S. P., Vanstone, V. A., Ware, A. H., McKay, A. C., Szot, D., and Russ, M. H. 1999. Measuring yield loss in cereals caused by root lesion nematodes (Pratylenchus neglectus and P. thornei) with and without nematicide. Aust. J. Agric. Res. 50:617-622.

Thompson, A. L., Mahoney, A. K., Smiley, R. W., Paulitz, T. C., Hulbert, S., and Garland-Campbell, K. 2017. Resistance to multiple soil-borne pathogens of the Pacific Northwest, USA is colocated in a wheat recombinant inbred line population. G3 (Bethesda) 7:1109-1116.

Thompson, J. P. 2008. Resistance to root-lesion nematodes (Pratylenchus thornei and P. neglectus) in synthetic hexaploid wheats and their durum and Aegilops tauschii parents. Aust. J. Agric. Res. 59:432-446.

Thompson, J. P., Brennan, P. S., Clewett, T. G., Sheedy, J. G., and Seymour, N. P. 1999. Progress in breeding wheat for tolerance and resistance to rootlesion nematode (Pratylenchus thornei). Aust. Plant Pathol. 28:45-52.

Thompson, J. P., Clewett, T. G., and O'Reilly, M. M. 1993. Tolerance and resistance in wheat to Pratylenchus thornei. Ninth Biennial Australasian Plant Pathology Conference, Hobart, Tasmania, Australia.

Thompson, J. P., Clewett, T. G., and O'Reilly, M. M. 2015a. Optimising initial population density, growth time and nitrogen nutrition for assessing resistance of wheat cultivars to root-lesion nematode (Pratylenchus thornei). Aust. Plant Pathol. 44:133-147.

Thompson, J. P., Clewett, T. G., and O'Reilly, M. M. 2015b. Temperature response of root-lesion nematode (Pratylenchus thornei) reproduction on wheat cultivars has implications for resistance screening and wheat production. Ann. Appl. Biol. 167:1-10.

Thompson, J. P., Mackenzie, J., and Amos, R. 1995. Root-lesion nematode (Pratylenchus thornei) limits response of wheat but not barley to stored soil moisture in the Hermitage long-term tillage experiment. Aust. J. Exp. Agric. 35:1049-1055.

Thompson, J. P., Mackenzie, J., and Sheedy, G. H. 2012. Root-lesion nematode (Pratylenchus thornei) reduces nutrient response, biomass and yield of wheat in sorghum-fallow-wheat cropping systems in a subtropical environment. Field Crops Res. 137:126-140.

Thompson, J. P., Owen, K. J., Stirling, G. R., and Bell, M. J. 2008. Root-lesion nematodes (Pratylenchus thornei and P. neglectus): A review of recent progress in managing a significant pest of grain crops in northern Australia. Aust. Plant Pathol. 37:235-242.

Vanstone, V. A., Hollaway, G. J., and Stirling, G. R. 2008. Managing nematode pests in the southern and western regions of the Australian cereal industry: Continuing progress in a challenging environment. Aust. Plant Pathol. 37: 220-234. 